\title{
Наше будущее - сетевые структуры
}

В.А. КРЮКОВ, член-корреспондент РАН, директор Института экономики и организации промышленного производства СО РАН, Новосибирск

Институт экономики и организации промышленного производства СО РАН в июне 2018 г. отмечает 60-летие. В своем интервью директор института В.А. Крюков рассуждает о судьбе тех научных школ, которые составили славу института в советские годы, размышляет о месте института в современной экономической науке, формулирует свое отношение к конкуренции и коллаборации с российскими и зарубежными научными организациями, рассказывает о наиболее перспективных современных разработках института.

Ключевые слова: ИЭОПП, наука, научная школа, сетевые исследования

- Валерий Анатольевич, 60-летний юбилей института хороший повод поговорить о векторе изменений тех подходов к исследованиям, которые отличали ИЭОПП со времен создания. Те научные школь, которые когда-то принесли институту славу, формировались в совершенно иной экономической, политической реальности. Как они трансформировались в наши дни?

- Институт - живой организм, который с самого начала развивался в непростой и внешней, и внутренней среде. Он был создан в составе Сибирского отделения Академии наук в соответствии с лучшими традициями академической науки (и это - не только мое мнение) и, как мне представляется, с самого начала его исследования выходили далеко за рамки экономической системы СССР того времени и были частью мировой экономической науки. Именно поэтому многие его подходы, разработки остаются актуальными независимо от внутренних и внешних потрясений.

Так, отдел социальных проблем института имеет «генетические корни» в российской аграрной экономической науке (которая в начале $\mathrm{XX}$ в. была одной из передовых в мире). Лидер и основатель отдела академик Татьяна Ивановна Заславская «повела» соратников дальше - от изучения проблем неравенства в оплате труда сельских жителей к исследованию неравенства в «обществе равных и свободных строителей коммунистического светлого завтра». Был сделан шаг от, казалось бы, узких экономических и социальных вопросов сельского хозяйства к исследованию проблем развития общества в целом. В результате сформировалась 
сибирская школа экономической социологии. Школа возникла как логическое и творческое развитие идей целой плеяды выдающихся отечественных ученых - А. В. Чаянова, В.Г. Венжера, А. В. Саниной и многих других.

Аналогичный путь был характерен и для школы региональных исследований, которые тоже составляют визитную карточку института благодаря трудам Александра Григорьевича Гранберга (он был директором ИЭОПП СО РАН в 1985-1991 гг.), Марка Константиновича Бандмана (он возглавлял отдел оптимизации территориальных систем в 1976-1989 гг.), Роберта Исаковича Шнипера, Бориса Павловича Орлова и их учеников. И я не могу сказать, что их работы или подходы в чем-то устарели. Да, сейчас много говорится о кластерах, в которых взаимосвязи и взаимодействия хозяйствующих субъектов формируются под влиянием «невидимой руки» - рыночных сил. Однако никто не отменял ни значения, ни роли государства в освоении и развитии пространства. Дирижистское, государственное начало в большей или меньшей степени характерно для всех стран Европы и Азии (в меньшей мере - для США), не говоря уже о дореволюционной России, где основным катализатором и движителем процессов продвижения, например, на Восток была государственная политика (как тут не вспомнить о сооружении Великой Сибирской железной дороги). Не случайно «родоначальник» учения о ТПК М.К. Бандман в советской региональной экономической науке был также и одним из наиболее активных участников международного сотрудничества, членом ряда международных научных организаций ученых-регионалистов.

Соединение глубокого знания особенностей пространственной организации экономики (наиболее существенных ее составляющих - транспорта (Б.П. Орлов), финансов и управления (Р.И. Шнипер), организации производственных связей (М.К. Бандман)) с методами количественного анализа и прогнозирования (А. Г. Гранберг с плеядой учеников) привели к новому качеству понимания роли и места пространства в решении проблем социально-экономического развития и страны и, в особенности, ее восточных регионов. Сейчас много говорится о повороте на Восток - для наших коллег это было очевидно много лет назад.

Еще одна научная школа, созданная в ИЭОПП Абелом Гезевичем Аганбегяном, - школа системного изучения и анализа моделирования отраслевых рынков (в современной терминологии). Данное направление выросло из возможностей применения современных математических методов к решению проблем отдельных секторов экономики и отдельных хозяйственных структур. В основе лежали также идеи выдающегося советского экономиста-математика Л.В. Канторовича - лауреата Нобелевской премии по экономике 1975 г. «за вклад в теорию оптимального распределения ресурсов» (совместно с американским коллегой Т. Купмансом). В рамках данного направления были найдены решения целого ряда важнейших народнохозяйственных и отраслевых проблем.

Увы, применение современных научных подходов к поиску оптимальных решений в тех или иных секторах экономики также со всей очевидностью показало, что наличие наилучшего априорного решения той или иной проблемы не гарантирует подобный результат апостериори (на практике). Велика роль стимулов, условий и всего того, что сейчас называется «трансакционным сектором экономики». Невозможно получить оптимальный план или производственную программу, устойчивую в течение сколь-нибудь реального промежутка экономического времени (т.е. периода функционирования созданных основных активов). Экономика - это динамичная и подвижная система отношений и связей, которые возникают в каждый момент времени.

Я как исследователь занимаюсь изучением проблем формирования и эволюции институциональных систем в сфере освоения и использования природных ресурсов. Думаю, что подобное направление с подобным содержанием могло возникнуть только в ИЭОПП СО РАН по той причине, что в той или иной степени оно основано на работах и на влиянии всех отмеченных выше научных школ и выдающихся предшественников.

Исследования института, несмотря на социально-экономическую направленность, никогда не были идеологически или политически ангажированными. Возможно, повышенное внимание уделялось месту государства в экономических процессах, но мне представляется, что и сейчас эта роль очень велика. В частности, никто, кроме государства, не может осуществить серьезные инвестиции для крупных инфраструктурных проектов (заметим, что М.К. Бандман высоко оценивал комплексную программу развития долины реки Теннесси в США, всецело основанную на ведущей роли государства и методах кейнсианского стимулирования экономического развития). Наша страна уже почти 30 лет строит 
рыночную экономику, но события последних лет показывают, что до сих пор отсутствует среда, в которой она может развиваться. Беда в том, что мы ушли от прямого всеохватывающего присутствия государства, но к методам, представляющим гибкий симбиоз его участия и тех возможностей, которые дают свобода выбора и готовность к принятию предпринимательского риска, так по-настоящему еще и не подошли (несмотря на повышенное внимание, например, к различным формам ГЧП).

Таким образом, на мой взгляд, институт всегда был частью мировой науки (конечно, с определенным акцентом на доминирующей роли государства в освоении и развитии пространства). Но его подходы, объекты и направления исследований в целом были всегда адекватны трендам соременной экономической науки.

- Какие изменения произошли с тех пор во внешней и внутренней среде? Как поддерживаются и развиваются обозначенные направления исследований? Стала ли другой организационная структура института?

- Сейчас меняется само представление о месте и роли научных организаций. Если раньше институт был самодостаточным учреждением со штатной численностью около 800 человек, с отделами, изучающими основные отрасли и секторы сибирской экономики, и довольно большими (по 30-50 человек в каждом) подразделениями в Тюмени, Красноярске, Кемерове, Барнауле и других городах, то сейчас в нем около 300 работников, и только половина из них - научные сотрудники. Я считаю, что это мировая тенденция - от самодостаточных организаций, ведущих полностью весь цикл исследований, наука постепенно переходит к сетевым структурам, предполагающим взаимодействие с коллегами, коллаборацию, сотрудничество, кооперацию, включение в разные альянсы. Институт становится коллективом, где сосредоточены ведущие эксперты, которые способны сотрудничать и кооперироваться с коллегами по всему миру, имеют опыт и признание, их приглашают в соответствующие организации и проекты.

Видоизменились и взаимоотношения с внешними структурами. Раньше научные институты выполняли масштабные работы и задания, связанные, например, с комплексной программой научно-технического прогресса. Сейчас, после почти 30-летних поисков, происходит возврат к той же схеме-вновь на государственном уровне разрабатывается прогноз научно-технологического развития, в рамках направлений которого определяется роль разных организаций, в частности РАН. Но теперь эта роль не всеобъемлющая - место института определяется его компетенциями, навыками и умениями, необходимыми для участия в проекте. И если недостаточно своих специалистов, надо уметь интегрироваться, особенно в рамках междисциплинарных исследований.

- Омущуаете ли вы спрос на фундаментальные экономические исследования? Или конъюнктурные задачи его в значительной мере подавили? Как академическому институту удается играть одновременно на этих двух досках?

- На мой взгляд, спрос на перспективные работы довольно большой. Они необходимы обществу, государству и бизнесу. Есть желание знать и понимать, что происходит и какие это открывает (или закрывает) возможности. Другое дело, что удовлетворение подобного спроса должно базироваться на многолетних исследованиях, ведь знание и понимание особенностей протекания социально-экономических процессов формируются десятилетиями. И вот здесь у нас возникают определенные противоречия. Грантовая система, ориентированная на краткосрочные работы, по сути, вступает в конфликт с требованиями фундаментального подхода. Но без фундаментальных заделов рано или поздно вы не сможете качественно выполнять эти гранты. В какой-то мере выручают комплексные программы РАН, в рамках которых финансируются переходящие из года в год темы государственного задания, что позволяет накапливать и приумножать знания. Пока эта система не отлажена и не так хорошо структурирована, как это было даже в советские годы, но мне кажется, магистральный путь где-то здесь - вычленение ядра ключевых фундаментальных направлений, которыми длительное время занимается институт, и на его основе-выполнение работ, связанных с потребностями экономики (преимущественно на так называемой внебюджетной основе).

Одна из главных проблем, возникающих при этом, - не потерять преемственность. Пока ситуация в институте более-менее удовлетворительная. Средний возраст сотрудников - около 50 лет. Но чтобы сделать систему более устойчивой, необходимо, чтобы ежегодно пять-семь, а лучше - десять молодых сотрудников приходили и закреплялись в институте. Вопрос в том, как создать мотивацию, сформировать у них видение своей траектории и жизни в науке? Раньше этапы научной карьеры были понятны 
на долгие годы. Сейчас такой уверенности на годы вперед у молодых коллег, как правило, нет. При этом у выпускников появились другие возможности: после бакалавриата или магистратуры можно поехать в Москву, из Москвы - по всему белу свету. Приходится конкурировать в борьбе за талантливых, ищущих, амбициозных.

В нашей стране, к сожалению, сейчас остра проблема «потерянного поколения», не накопившего достаточный социальный опыт. Что греха таить - иждивенчество имеет место и в академической среде. Часто приходится слышать: дайте денег, дайте зарплату. При этом многие не понимают, что нигде в мире, даже в развитых странах, наука не является тихой обеспеченной гаванью.

Думаю, не за горами тот день, когда мы будем рекрутировать научных сотрудников не только из НГУ, но и из других городов, и даже стран мира. Например, около года назад некий молодой человек из Индии написал о своем желании заниматься в нашем институте ресурсной экономикой. Его не пугает наш климат, ему интересна тематика. К сожалению, пока мы не готовы предложить иностранцам достойные условия для жизни и связанные с этим социальные гарантии, но пригласить на короткий период сложившихся исследователей вполне реально, особенно, если кооперироваться с НГУ, у которого есть мегагранты, позволяющие пригласить на три года человека на приемлемых условиях

- В какой конкурентной среде действует институт? Крупные проекты, требующче государственного финансирования, выполняют столичные исследовательские структуры, часто имеюшие лоббистские возможности, а для более мелких проектов, например, по стратегическому планированию, которым сейчас обязали заниматься даже муниципальные образования, чаше обрашаются в небольшие организачии, которых развелось очень много. Каково место сибирского научного института на рынке коммерческих исследований?

- Да, нам очень сложно работать как, например, «на рынке» разработки региональных стратегий, так и оказания консалтинговых услуг по сопровождению текущих бизнес-процессов в компаниях различного уровня и размера. Среди причин не только и не столько инерция академического учреждения, сколько кардинальное изменение профессиональной среды «благодаря» тому во многом, что в 1990-2000-е гг. в ту и другую сферы пришли новые «игроки». В первом случае стал важен не столько (и не только) уровень глубины и обоснованности предложений стратегического характера, сколько умения и навыки «по продвижению» данных выводов «в жизнь»-прежде всего, в форме распоряжений и решений органов власти. Во втором случае конкуренцию составляет значительная «прослойка» «новоиспеченных ученых». Снижение требований многих ученых советов к соискателям степеней привело к тому, что появилось множество поверхностных, далеких от исследовательской деятельности «специалистов», научившихся говорить наукообразным языком, за которым мало что стоит.

Видимо, со временем нам придется, как это делается во всем мире, после научной степени через запятую указывать, каким научным советом эта степень присуждена. В США можно получить степень PhD за полгода, а в Гарварде для этого потребуется от пяти до семи лет. Но диплом Гарварда - это один статус и совсем другая оплата, диплом же третьеразрядного университета (совета) не обеспечивает ни статуса, ни приемлемой оплаты.

Не менее важная для нас проблема в том, что центры выработки и принятия решений в большинстве сколь-нибудь значимых бизнес-структур, работающих на территории Сибири, находятся далеко за ее пределами. Вот и приходится иногда слушать «лекции» заезжих бизнес-коучей (тренеров), залетающих к нам на «хвосте» программ переподготовки кадров управления, которые проводятся в Москве или (в значительно меньшей степени) в Санкт-Петербурге.

Но я считаю, что создание муниципальных и региональных стратегий - это вообще не уровень академического института. Сегодня это очень сильно зарегламентированная законодательством, шаблонная, нетворческая работа. Научная организация может в ней участвовать лишь по трем соображениям - для обучения молодежи, получения дополнительных (но никак не основных!) внебюджетных доходов и актуализации контактов с органами управления на местах.

Совсем другое дело - поисковые работы стратегического характера, которые создаются не по регламентам. Это достойное приложение сил и интересный опыт, и за такие заказы действительно стоит бороться. Так, в конце 2017 г. наш институт подготовил для Правительства РФ, РАН и ФАНО отзыв на проект Стратегии пространственного развития России. Через несколько 
месяцев меня пригласили на встречу с вице-премьером Д.Н. Козаком, курировавшим в Правительстве предыдущего созыва проблемы регионального развития, для обсуждения принципиальных вопросов и предложили войти в соответствующую правительственную комиссию.

Проблема не столько в конкуренции, сколько в умении вступать в продуктивные альянсы с другими организациями. Сейчас мы пытаемся переформатировать отношения с московскими, петербургскими коллегами, занимаемся подготовкой соглашения Сибирского отделения РАН с Республикой Татарстан.

Эффективные контакты с внешней средой предполагают проактивную позицию: писать хорошие научные статьи и отчеты необходимо, но надо найти баланс научных исследований с их практическим применением. Помню, в студенческие времена на популярнейших в НГУ «экономических средах» горячо обсуждался вечный для науки вопрос - должен ли ученый быть организатором? Сегодня, мне кажется, ответ очевиден, и вопрос нужно переформулировать: как создать в институте среду, которая бы стимулировала и поощряла не только приумножение научных знаний, развитие исследований, но и способность быть на острие возникающих проблем?

- Расскажите о наиболее интересных, с вашей точки зрения, проектах, направлениях исследований, которые ведет институт сегодня. Какие из них считаете наиболее перспективными?

- Основное направление исследований - роль и место пространственных факторов и условий в социально-экономическом развитии России и, в особенности, ее восточных районов. Институт занимает уникальное положение - и в центре огромной страны, и в научном экономическом сообществе. Ему просто «на роду написано» заниматься пространственными аспектами макроэкономического развития России. Здесь мы в огромном долгу и перед страной, и перед обществом. В настоящее время в «официальной экономической науке» (об этом мы не раз писали на страницах «ЭКО») приобрели популярность идеи новой урбанистики, новой экономической географии, сформулированные нашими зарубежными коллегами применительно к совершенно другим условиям.

С этим направлением исследований связано изучение таких проблем, как связанность пространства (в экономическом, финансовом, социальном измерениях). Каковы современные особенности взаимодействия, например, сырьевых территорий Севера и Востока с обрабатывающими и обеспечивающими территориями Юга и Запада страны? Как развивается трансграничное взаимодействие территорий востока страны с Китаем и странами Юго-Восточной Азии (новое для нас направление). Или такое преломление темы: «анализ экономических взаимодействий федеральных округов РФ, проведенный в 2016 году с помощью модифицированной многорегиональной межотраслевой модели, показал существенную неоднородность российского экономического пространства. Основными регионами-донорами, потребление общественного продукта в которых заметно меньше их производства, являются Северо-Западный, Дальневосточный, Сибирский и Уральский федеральные округа. При этом Центральный федеральный округ - ярко выраженный реципиент» (руководитель В.И. Суслов).

В русле исследования проблем пространственного развития изучаются и проблемы развития Арктической зоны РФ. Так, на обширном статистическом, историческом, а также межстрановом материале было показано, что ее значение и роль для экономики страны тем больше и тем весомей, чем теснее процесс реализации проектов связан с развитием, прежде всего, промышленных и научно-образовательных центров, расположенных в южной зоне востока России. В частности, с использованием разработанного подхода институтом в 2017 г. выполнена большая исследовательская работа по Якутии (совместно с коллегами из Северо-Восточного федерального университета, г. Якутск). Для обоснования главных выводов и рекомендаций были применены методы когнитивного анализа.

Важная особенность отмеченных выше работ состоит в том, что они «доведены» до уровня рекомендаций и предложений практического характера. Этому во многом способствует, например, то, что под эгидой аппаратов полномочных представителей Президента РФ в Сибирском и Уральском федеральных округах создана соответствующая рабочая группа - по продвижению работ, товаров, услуг предприятий и организаций данных территорий при реализации проектов в Арктике.

Чрезвычайно интересным и многообещающим направлением исследований является изучение влияния новых технологий на изменение характера и направлений взаимодействия экономических 
субъектов. К сожалению, в процессе реформирования отечественной экономики не был принят во внимание тот факт, что созданные и реализованные технические и технологические решения были ориентированы на координацию исключительно в рамках системы жесткой вертикальной иерархии не только принятия, но и реализации экономических решений. Как следствие, - страна получила наблюдаемый опережающий рост издержек и доминирование монополий в жизненно важных секторах экономики.

Тем не менее, «вследствие развития новых технологий, формы взаимодействия и взаимопроникновения, например, угольной и энергетической отраслей претерпели существенную трансформацию - от простой цепочки поставок товаров до интегрированных комплексов и кластеров... Большинство экономических задач, связанных с прогнозом развития и размещения объектов отраслевого комплекса, подчиняются иерархическому моделированию и взаимодействуют с тремя уровнями принятия решений (макро-, мезо- и микроуровни), при этом существующие оптимизационные модели "странового" или макрорегионального уровня не позволяют в полной мере учесть региональные особенности и оценить влияние небольших отраслевых проектов» (руководители Н.И. Суслов и В.Н. Чурашев).

К числу, несомненно, важных выполненных институтом работ также следует отнести разработку научных основ системы решений и мероприятий стратегического развития - как территорий - субъектов Федерации, так и отдельных территориальных образований (в статусе как агломераций, так и отдельных городов) (руководители В.В. Кулешов и В.Е. Селиверстов).

- Bbl много общаетесь с руководителями зарубежных институтов, аналогичных нашему. ИЭОПП как академическая организация движется в едином тренде со всем миром или у него свое место, свой путь?

- У нас свое место, хотя бы потому, что существующие универсальные системы общенаучных, общетеоретических взглядов на пространственную тематику, на развитие экономики в каждом регионе мира формируются с учетом особенностей конкретной территории. В 2017 г. у меня был ряд встреч с зарубежными коллегами. Могу сказать, что на конференции на Юконе (в рамках обсуждения опыта Канады по случаю 150-летия ее государственности) на повестке дня были очень схожие с нашими проблемы-удаленность, доминирование сырьевых корпораций, «ножницы цен», нарастание проблем охраны окружающей среды, экономические права и полномочия муниципалитетов и интересы коренного населения. То есть проблемы примерно те же. Но при этом специфика в значительной степени своя. То же самое - при посещении провинции Финнмарк в Норвегии, северных районов Скандинавии, Республики Корея, провинций Китая. То, что и как мы делаем, какой инструментарий используем, в целом соответствует современным представлениям о месте и роли экономической науки.

У нас, повторю, очень выигрышная позиция, мы просто обязаны стать центром большой сетевой структуры на востоке страны. Территория востока страны - это уникальный полигон для того, чтобы убедительно и содержательно представлять разрабатываемые нами подходы и идеи. Именно в этом качестве нас видят и зарубежные коллеги. Наше будущее как научной организации связано с тем, что Сибирь важна не только для России, это значительная часть и Азии, и мира в целом, и это определяет спрос на те проблемы, которыми мы занимаемся. Но представление этих проблем и их адекватная оценка в существенной степени зависят от наших собственных усилий. Непродуктивно и недальновидно искать проблемы и сложности в нашей экономике исключительно вовне.

За последние 30 лет стало особенно ясно, что многие интеллектуальные заделы - прежде всего, основанные или на прежнем понимании движущих сил социально-экономических процессов или на копировании чужого опыта, по большому счету исчерпаны. Это касается и науки, и практики, и именно это предопределяет спрос на будущее. А в этих условиях перспективы у института, на мой взгляд, очень неплохие.

\section{Summary}

Kryukov V.A., Institute of Economics and Industrial Engineering, SB RAS, Novosibirsk

\section{Networks are Our Future}

Institute of Economics and industrial Engineering SB RAS celebrates its 60th anniversary this year. Director of IEIE Prof. Dr. Valery A. Kryukov during his interview talks about the fate of scientific schools that have contributed to institute's fame around the world in the Soviet period, reflects on IEIE's place in the history of modern economic science, formulates his position with regard to competition and collaboration with national and foreign scientific organizations, tells about the most promising modern developments of the institute.

IEEP; science; scientific school; network research 